\title{
Significance of Oxirane Rings in Epoxidized Palm Oil and Effects on the Coating Performance: Comparison between Epoxidized Unripe Palm Oil and Epoxidized Used Cooking Oil towards Adhesion Performance
}

\author{
Nurul Hazirah Aina Hasnan, Najmiddin Yaakob*, Muhammad Nadzmi Abu Kassim, and Umie Amira \\ Mohd Noh
}

Faculty of Chemical Engineering, Universiti Teknologi MARA (UiTM), Shah Alam 40450, Selangor, Malaysia

\author{
* Corresponding author: \\ tel: $+60-194902526$ \\ email:najmiddin@uitm.edu.my \\ Received: June 14, 2019 \\ Accepted: January 8, 2020 \\ DOI: $10.22146 /$ ijc.46619
}

\begin{abstract}
In this study, epoxy coatings made up from petroleum-based epoxy resin mixed with two different types of palm oils were prepared and compared. The commercial epoxy resin based on diglycidyl ether of bisphenol A (DGEBA) were formulated with epoxidized unripe palm oil (EPO) and another one with epoxidized used cooking oil (ECO) at four different ratios (0:100, 10:90, 20:80 and 30:70). The EPO and ECO were prepared through generated in situ of performic acid $(\mathrm{HCOOH})$ and hydrogen peroxide $\left(\mathrm{H}_{2} \mathrm{O}_{2}\right)$ by a fixed molar ratio of 1:5:4 mol/mol (EPO/ECO: $\mathrm{HCOOH}: \mathrm{H}_{2} \mathrm{O}_{2}$ ). The reaction took place at constant temperature $\left(45^{\circ} \mathrm{C}\right)$ with continuous stirring for $150 \mathrm{~min}$ to obtain 95.5\% oxirane conversion with $90.0 \%$ yield. The EPO and ECO were characterized by using Fourier Transform Infrared (FTIR) spectroscopy analysis. X-Cut and Cross-Cut methods were used in the test performance of adhesion strength. The results obtained from adhesion test for EPO were good as the coatings only experienced small trace of peeling. On the other hand, only minimal performances were obtained from the ECO coated metal. This was due to the presence of oxirane in EPO as compared to that of in ECO. EPO has a potential to replace petroleum-based resin in epoxy coating formulation according to its remarkable performances.
\end{abstract}

Keywords: epoxidized unripe palm oil; epoxidized used cooking oil; epoxy coating; epoxidation; adhesion performance

\section{- INTRODUCTION}

Bio-based materials recently received more attentions in product synthesis and manufacture especially in paint and coating industry. Escalated concern on depletion of fossil fuel and petroleum price has sparked widespread interest in alternative energy. Furthermore, the harm caused to the environment due to excessive use of fossil fuel has also contributes into awareness for more sustainable and environmentally friendly alternatives. Due to this, a research has been made by introducing biobased materials into epoxy coating formulation in order to minimize or eliminate the dependency towards petroleum-based materials. However, bio-based materials have lower properties than the petroleum-based materials. Thus, in order to sustain the level of mechanical properties, the coating formulation was formulated by varying the ratio between the bio-based materials and petroleum-based materials.

Epoxy resin is known as the best barrier-coating material in industry due to their toughness, flexibility and high resistance to chemical [1]. Diglycidyl ether of bisphenol A (DGEBA) is a common epoxy resin used in formulating epoxy coating due to their high strength, excellent corrosion protection, and good adhesion to most surfaces [2]. However, DGEBA is carcinogenic that can cause tumor [3] and could affect men reproductive system [4]. The structure of DGEBA is shown in Fig. 1.

Moreover, DGEBA is a petroleum-based product which is poorly biodegradable and usually causing increased in carbon dioxide emissions during the manufacturing process. Therefore, consumers are now turning to eco-friendly ingredient as the main component 


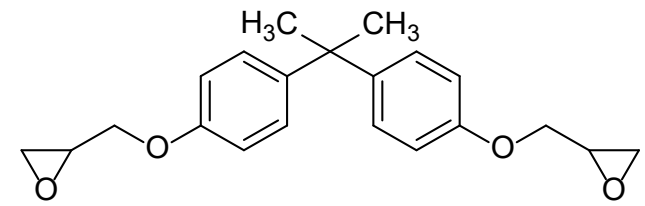

Fig 1. Structure of DGEBA [5]

in their coating material for better environment and health. Bio-based materials such as vegetable oils are safer and more beneficial because they are renewable, easily biodegrade and does not release a significant amount of greenhouse gas during manufacturing process [6].

The past history shows that the utilization of polymers based on vegetable oils such as Annona squamosa oil [7], Mesua ferrea L. seed oil [8], soybean oil [9], and palm oil [10] drew a great amount of attentions and supports from researchers, technologist, manufacturers and users. Vegetable oils are an excellent choice for the synthesis of bio-based polymers as they are biodegradable, non-toxic, non-depletable, non-volatile and most importantly low-priced and readily available in large quantities. As one of the world's leading producer of palm oil, Malaysia has high availability of palm oil. Palm oil is a type of edible vegetable oil that is produced from palm fruit of oil palm tree. Palm oil mainly consist of triglycerides, vitamin E, carotenoids, phytosterols, phospholipids, free fatty acids, gums, and oxidation products [11-12].

To increase the acceptability of palm oil for human consumption, palm oil undergoes refining process to remove the impurities such as undesirable odor, flavor, and color. The refined palm oil is so-called palm olein. Palm olein is largely use as cooking oil because of its stability at high temperature while at the same time has high antioxidant and limited amounts of unsaturated fatty acids [12]. Palm olein consists of oleic acid (39-45\%) and linoleic acid (10-13\%). Unsaturated fatty acids and saturated fatty acids also exist in approximately equal proportion in palm olein [13]. Repetition in using cooking oil during cooking and frying can cause deterioration of cooking oil making it no longer usable [14]. Cooking oil eventually is thrown away as waste without proper treatment. The accumulation of disposed used cooking oil polluted the environment and caused problem to sewage system because at low temperature, the oil will be solidified and clogged the sewage system [15].

In oil palm productions, quality is always be determined by its texture, shape and color. In general, palm fruits turn from dark purple to reddish orange at the apex of their ripening. The rule of thumb for good quality practices is that, only ripe fresh fruit bunch (FFB) of oil palm are harvested and then dispatched to mills within $24 \mathrm{~h}$ after harvesting. The problem of poor quality FFB in the market can be minimized if they abide by the rules. However, in the FFB market, this basic principle is not strictly followed. Producers fail to ensure that only ripe FFB are harvested and left them mixed with the unripe FFB. The usual oil extraction rate for a ripe fruits bunches from a mature tree is between 22-24 percent, or 220-240 kg of oil per tonne of fresh fruit bunches [16]. On the contrary, under-ripe fruits bunches contain less oil due to long stalks that soaked up the oil and therefore reduce the oil extraction rate. In order to increase the oil recovery in palm oil mill, the extraction of residual oil from unripe FFB is important. Based on these facts, in this work the used cooking oil and unripe fresh fruit bunch of palm oil is used to develop a new coating material through epoxidation process and subsequently evaluate the resulting coating film's properties and performances.

Epoxidation process is a process where the unsaturated carbon bond present in the palm olein is chemically modified into a value-added product by addition of oxirane ring (Fig. 2). It is desirable to achieve a high oxirane oxygen value and lower iodine value as these criteria are considered to be of better quality [17]. The epoxidation process involves electrophilic addition mechanism as shown in Fig. 3. Epoxidation reaction as

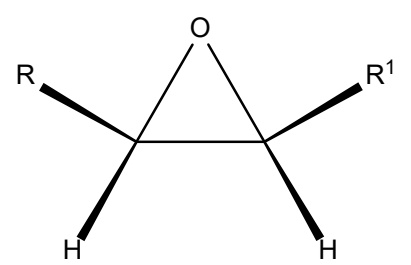

Fig 2. Structure of oxirane ring [10] 
<smiles></smiles>

Fig 3. Epoxidation of unsaturated bond [17]

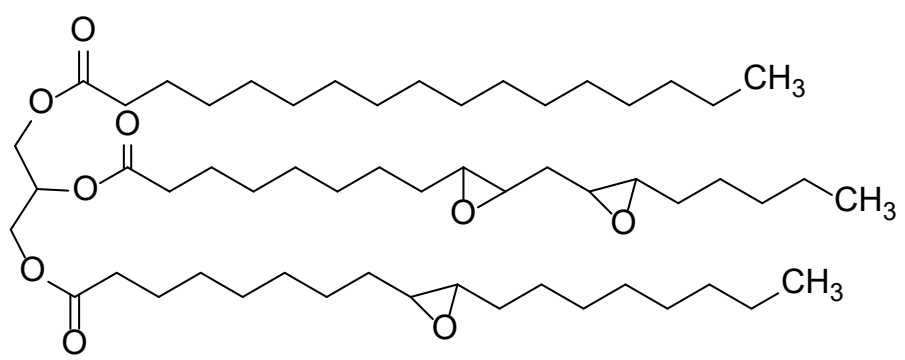

Fig 4. Structure of triglyceride after epoxidation with oxirane highlighted in green

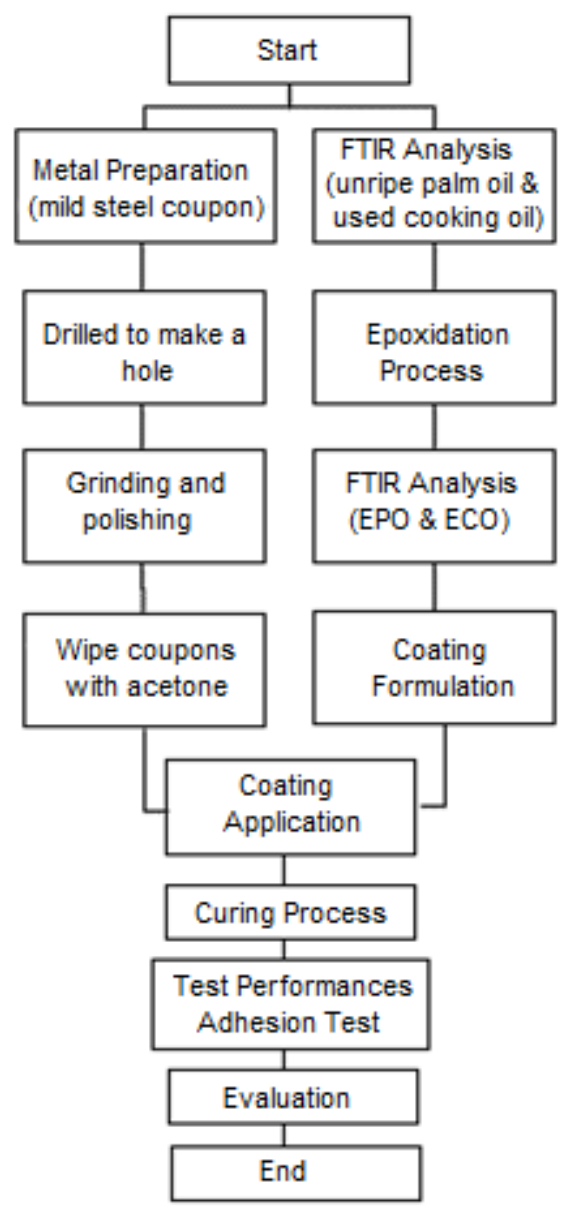

Fig 5. Overall process flow

shown in Fig. 3 takes place in similar way with unsaturated fatty acid structure. Oxirane ring forms at the unsaturated bond $(\mathrm{C}=\mathrm{C})$ to produce an epoxidized palm olein as shown in Fig. 4.

In this research, the epoxidized unripe palm oil (EPO) and epoxidized used cooking oil (ECO) will act as an additional material to reduce the toxicity of the current epoxy coating formulation. The bio-based epoxy coating was produced by varying the formulation into four different ratios (10:90, 20:80, and 30:70) of EPO/ECO to DGEBA. The overall goal is to develop a new coating material based on epoxidized unripe palm oil (EPO)/epoxidized used cooking oil (ECO) and Diglycidyl Ether of Bisphenol A (DGEBA) as well as to evaluate the performance of the new coating material based on their adhesion performance.

\section{- EXPERIMENTAL SECTION}

Test panel for coating performance testing was prepared early before coating application. Unripe palm oil and used cooking oil undergoes epoxidation process before can be used in coating formulation. Observation was made to evaluate the performances for each coating with different formulation. Fig. 5 shows the general steps for this process.

\section{Materials}

Formic acid (98-100\% purity) and titanium (IV) oxide powder were bought from Merck, Germany. Cycloaliphatic amine adducts (Isophorone diamine with 
$\geq 99 \%$ purity) and diglycidyl ether of bisphenol A were purchased from Sigma-Aldrich, USA. Used cooking oil was obtained from domestic waste. Unripe palm oil was obtained from Prof. Dr. Alawi Sulaiman from Faculty of Plantation and Agrotechnology UiTM Shah Alam. Hydrogen Peroxide ( $\geq 99 \%$ purity) was supplied by the chemistry laboratory in Faculty of Chemical Engineering, UiTM Shah Alam. Riken sandpaper grade 80, 180 and mild steel plate with dimension $60 \times 60 \times 3 \mathrm{~mm}$ were bought from hardware store in Seksyen 7, Shah Alam.

\section{Instrumentation}

Fourier Transform Infrared Spectrometer (Brand: Perkin Elmer Model: Spectrum 100), TQC Sheen wet film thickness gauge (Test Kit CC1000) follows ASTM D4414, ASTM D1212 \& ISO 2808, DPM-816 digital coating thickness tester, TQC Sheen Cross-Cut cutter, mixer, dipcoater machine, acrylic container, knife, steel ruler and grinding/polishing machine.

\section{Procedure}

\section{Epoxidation of unripe palm oil and used cooking oil}

A molar ratio of unripe palm oil/used cooking oil:formic acid:hydrogen peroxide $(1: 5: 4 \mathrm{~mol} / \mathrm{mol})$ was used in this epoxidation process with the mixture was heated and maintained at $45{ }^{\circ} \mathrm{C}$ [17]. Formic acid and hydrogen peroxide were mixed simultaneously in other container before added into the unripe palm oil/cooking oil. During addition of formic acid and hydrogen peroxide into unripe palm oil/used cooking oil, the addition action was done by slowly by adding drop wise of the mixture into the unripe palm oil/used cooking oil. The mixture was mixed homogeneously by using mechanical mixer for $150 \mathrm{~min}$. A sample of unripe palm oil and used cooking oil before and after epoxidized were taken for Fourier Transform Infrared Spectroscopy (FTIR) analysis. The spectrum of unripe palm oil and used cooking oil before and after epoxidized were then compared and analyze for the presence of oxirane ring.

\section{Characterization of palm oils derivatives}

Fatty acid profiles of oils were obtained by using a FTIR spectrometer (Perkin Elmer Model; Spectrum 100) equipped with a deuterated triglycine sulphate (DTGS) as a detector and a $\mathrm{KBr} /$ germanium as beam splitter, interfaced to Computer operating under Windows-based, and connected to software of the OMNIC operating system (Version 7.0 Thermo Nicolet). A few drops of each sample were positioned in contact with attenuated total reflectance (ATR) on a multi-bounce plate of crystal at controlled ambient temperature $\left(25^{\circ} \mathrm{C}\right)$. The ATR plate was carefully cleaned in situ by rubbing with acetone and dried with soft tissue before filling in with the next sample, and made it possible to dry the ATR plate. The plate cleanliness was verified by collecting a background spectrum and compared to the previous one. These spectra were recorded as absorbance values at each data point.

\section{Formulation of coating}

Blend of epoxidized unripe palm oil/used cooking oil and epoxy resin were prepared with a weight ratio 0:100, 10:90, 20:80, and 30:70 (EPO/ECO:DGEBA) in different beakers. The mixture was mixed using mechanical stirrer at $400 \mathrm{rpm}$ until no phase separation was observed. Then, titanium dioxide powder which act as a pigment was added into all the binder mixture produced at weight ratio of 1:0.5 (Binder: $\left.\mathrm{TiO}_{2}\right)$. The mixture was then mixed using mechanical mixer at mixer speed of 1010 revolution per minute (rpm) until homogenous phase obtained at approximately $1 \mathrm{~h}$. Finally, cycloaliphatic amine adduct as a crosslinking agent was added at a weight ratio of 1:0.25 (binder:amine). The mixture of binder and amine was then mixed using mechanical mixer at $400 \mathrm{rpm}$ until no phase separation was observed.

\section{Preparation of test panel}

Sand paper no. 80 was used to remove any layer of rust and pitting from the surface of test panel. Test panels were then lightly abraded using sandpaper no. 180 and wiped with acetone to remove metal dust that was produced from abrasion before coating application.

\section{Coating application}

Coating was applied using Motor-Driven Dip Coater RDC 15 Application as referred to ASTM D82395. A custom-made acrylic container was used in order to effectively coat the test panel and in the same time without using excessive amount of coating material. The 
coating speed was kept constant for all test panels to maintain uniform thickness among all coating. Wet film thickness was measured using TQC Sheen wet film thickness gauge. Three readings were taken at each surface of test panel. Once desired wet film thickness was obtained, the coated test panels were left in laboratory under room temperature and standard condition to let the coating undergoes curing process at ambient temperature for 7 days [10].

\section{Coating performance test}

Adhesion test. After the coated test panel cured for 7 days, adhesion performance test was done in order to determine the degree of adhesion. X-Cut and Cross-Cut Tape Test were used to rate adhesion performance by referring to ASTM D3359-09. The adhesion performance was rated based on classification provided in ASTM D3359-09 in Table 1 and Table 2.

\section{- RESULTS AND DISCUSSION}

\section{Characterization Tests}

Fourier transform infrared spectroscopy (FTIR) technique was performed to identify the chemical bonds existed in the unripe palm oil and used cooking oil before and after epoxidation process.

Table 1. X-Cut Tape Test adhesion classification

\begin{tabular}{cl}
\hline Classification & \multicolumn{1}{c}{ Explanation } \\
\hline 5A & No peeling or removal \\
4A & Trace peeling or removal along incisions or at their intersection \\
3A & Jagged removal along incisions up to $1.6 \mathrm{~mm}(1 / 16 \mathrm{in}$.$) on either side$ \\
2A & Jagged removal along most of incisions up to $3.2 \mathrm{~mm}(1 / 8 \mathrm{in}$.$) on either side$ \\
1A & Removal from most of the area of the X under the tape \\
0A & Removal beyond the area of the X \\
\hline
\end{tabular}

Table 2. Cross-Cut Tape Test adhesion classification

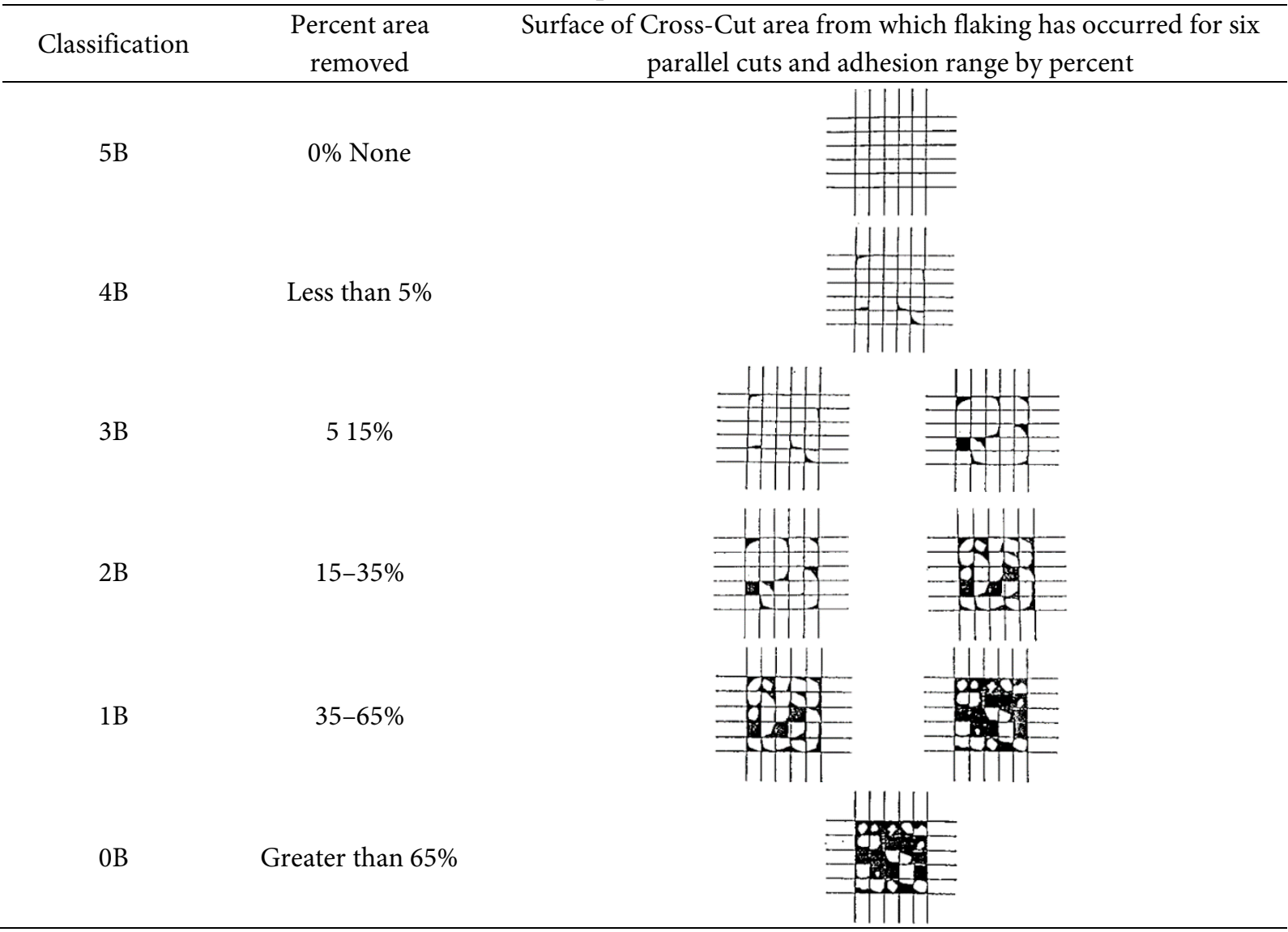


The spectrum of unripe palm oil as shown in Fig. 6(a) showed a stretching vibration peak of $=\mathrm{CH}\left(3003 \mathrm{~cm}^{-1}\right.$, a stretch of C-H was observed between $2921-2852 \mathrm{~cm}^{-1}$, a carbonyl stretch $\mathrm{C}=\mathrm{O}$ at $1743 \mathrm{~cm}^{-1}$, and unsaturation peak $\mathrm{HC}=\mathrm{CH}$ (cis) at wavenumber $1650 \mathrm{~cm}^{-1}$. The peak at $3003 \mathrm{~cm}^{-1}$ corresponds to the level of unsaturation that disappears as the double bonds are converted and used; thus, correlating with the epoxide peak at $844 \mathrm{~cm}^{-1}$ as shown in Fig. 6(b). The same result generated was also demonstrated in the previous research [17]. The formation of epoxy group in the chemical structure of the epoxidized unripe palm oil indicates that the epoxidation process was successfully done.

Fig. 7(a) shows the spectrum profile of cooking oil before undergoes epoxidation process. A stretch of $\mathrm{C}-\mathrm{H}$ was observed between $2921-2852 \mathrm{~cm}^{-1}$. The spectrum shows carbonyl stretch at $1743 \mathrm{~cm}^{-1}$ and methyl bending at $1464 \mathrm{~cm}^{-1}$. Presence of nitrogenous compound is shown at $1542 \mathrm{~cm}^{-1}$ and methylene group at $721 \mathrm{~cm}^{-1}$. Bending of $\mathrm{C}-\mathrm{H}$ was observed at $1377 \mathrm{~cm}^{-1}$. Existence of $\mathrm{C}-\mathrm{O}$ stretching and bending of $\mathrm{O}-\mathrm{H}$ were found at 1159 $\mathrm{cm}^{-1}$ and $1116.95 \mathrm{~cm}^{-1}$ respectively.

While, Fig. 7(b) shows the spectrum profile of cooking oil after the epoxidation process. Based on the spectrum profile of ECO, there is no oxirane ring formed in the fatty acid structure from the epoxidation process as the oxirane ring should produce a trough between $833-841 \mathrm{~cm}^{-1}$ [18-19]. Fig. 8 shows the summary of adsorption band of unripe palm oil and used cooking oil before and after epoxidation. Used cooking oil that was

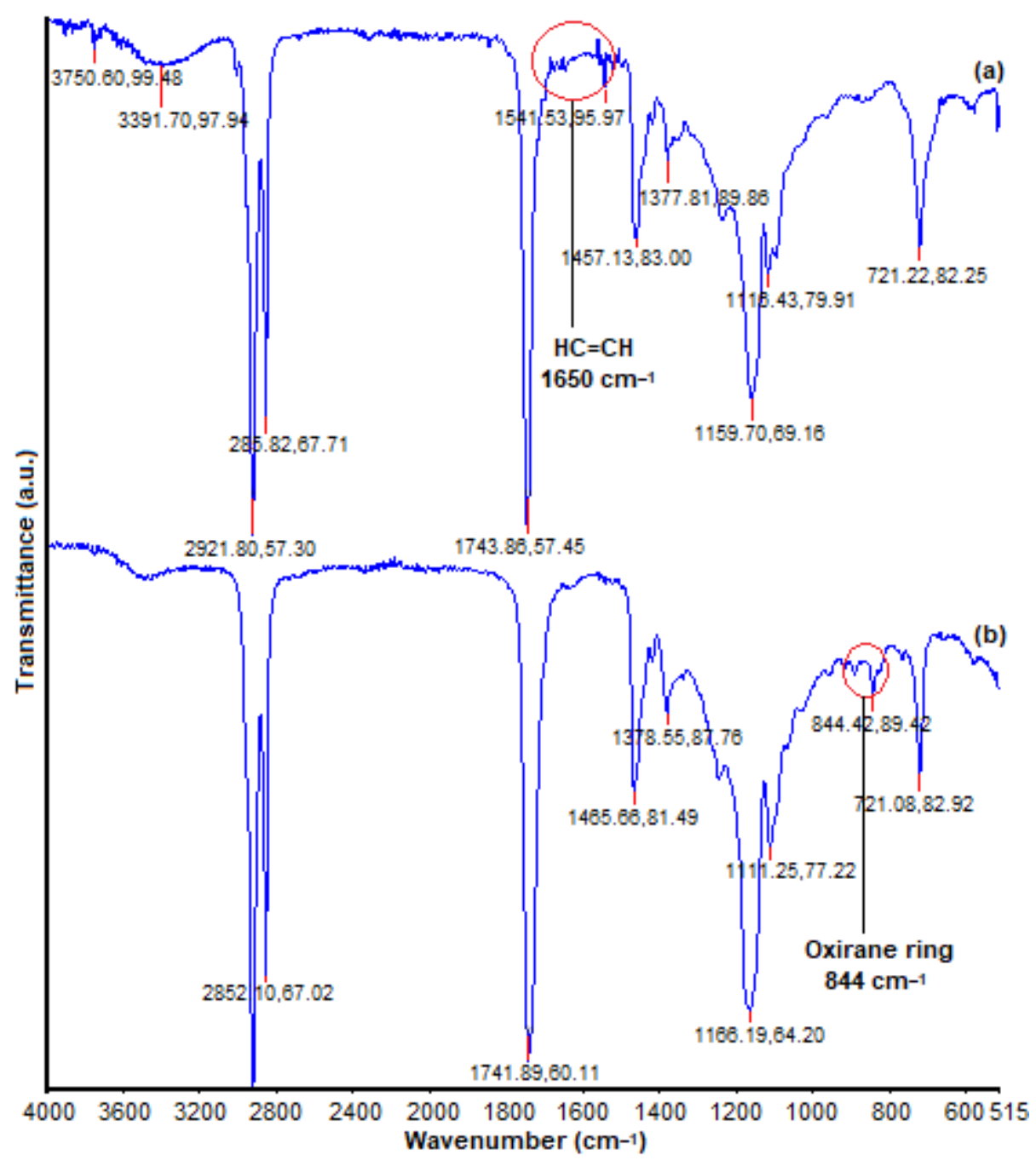

Fig 6. FTIR spectrum of (a) unripe palm oil and (b) epoxidized unripe palm oil 


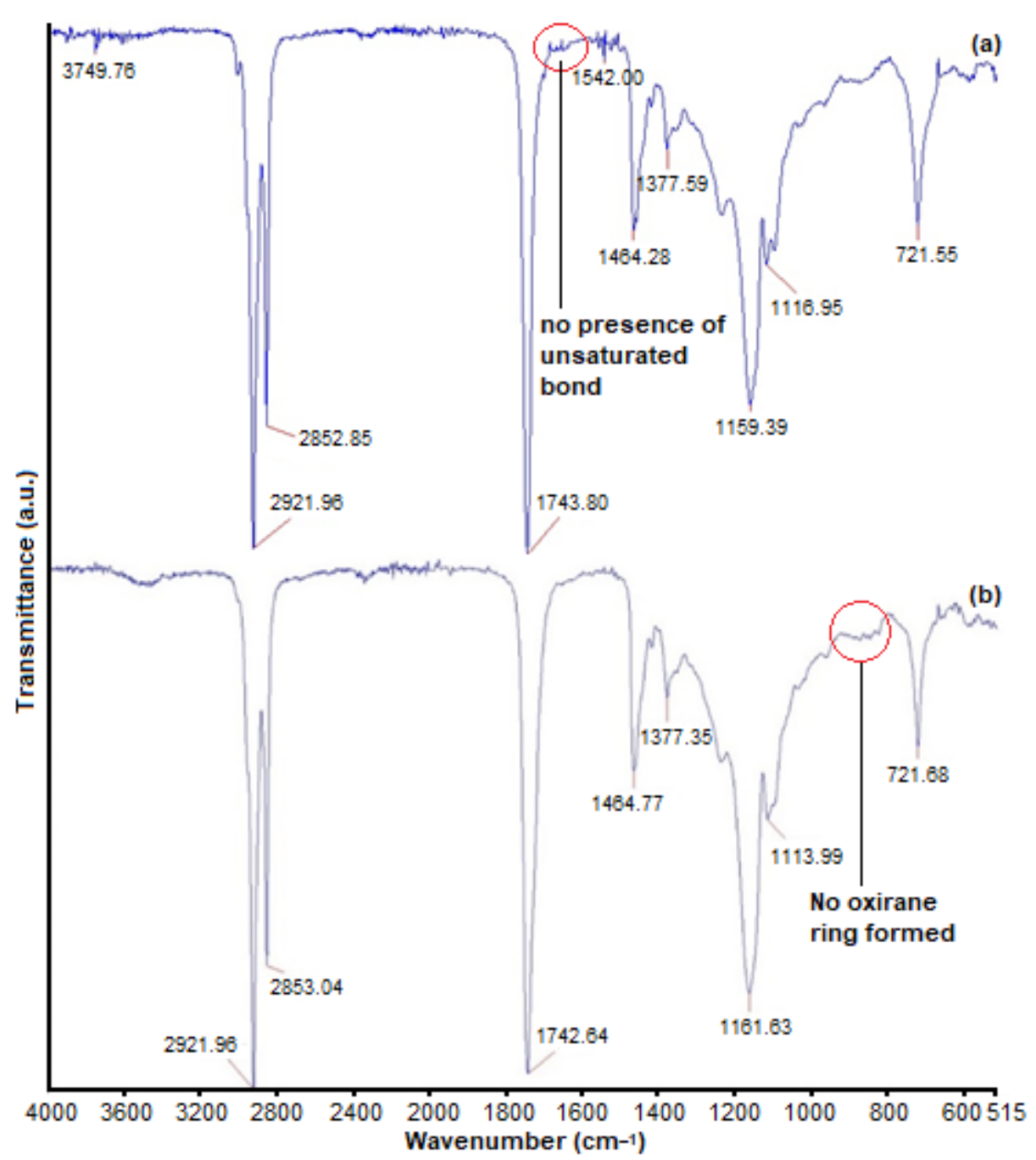

Fig 7. Spectral analysis of (a) used cooking oil and (b) epoxidized used cooking oil

Table 3. Summary of absorption band of unripe palm oil and used cooking oil before and after epoxidation process

\begin{tabular}{lcccc}
\hline Group & $\begin{array}{c}\text { Unripe palm oil } \\
\left(\mathrm{cm}^{-1}\right)\end{array}$ & $\begin{array}{c}\text { Epoxidized unripe } \\
\text { palm oil }\left(\mathrm{cm}^{-1}\right)\end{array}$ & $\begin{array}{c}\text { Used cooking oil } \\
\left(\mathrm{cm}^{-1}\right)\end{array}$ & $\begin{array}{c}\text { Epoxidized used } \\
\text { cooking oil }\left(\mathrm{cm}^{-1}\right)\end{array}$ \\
\hline $\mathrm{N}-\mathrm{H}$ str & 3391 & 3394 & 3749 & - \\
$=\mathrm{CH}$ str & 3003 & - & 2921 & 2921 \\
$\mathrm{HC}=\mathrm{CH}$ (cis) & 1650 & - & - & - \\
$\mathrm{C}=\mathrm{O}$ & 1743 & 1741 & 1743 & 1742 \\
Oxirane ring & - & 844 & - & - \\
\hline
\end{tabular}

collected from domestic household might consist of very low amount of unsaturated fatty acid or none at all. Existence of unsaturated fatty acid in the cooking oil is crucial for epoxidation process because unsaturated fatty acid provide reactive site for epoxidation process to complete [20]. Non-existence of unsaturated fatty acid in cooking oil is due to decomposition process of unsaturated fatty acid during frying process [14-15].

\section{Adhesion Performance Test}

The coated test panel undergoes adhesion performance test in order to determine the degree of 
adhesion performance. X-Cut and Cross-Cut Tape Test were used to rate adhesion performance by referring to ASTM D3359-07 [21]. The adhesion performance was rated based on classification provided in Table 1 and 2 as shown earlier.

\section{X-Cut Tape Test}

The results obtained from the X-Cut Tape Test for epoxidized unripe palm oil (EPO) coated metals were good as the coatings only experienced small trace of peeling as seen in Table 4. Formulation 0:100 serves as control which produced best performance with adhesion classification as 5A. Formulation 10:90 and 20:80 are both classified as 4A. Formulation 30:70 also produced the best adhesion classification which is $5 \mathrm{~A}$. On the other hand, results from X-Cut Tape Test for ECO coated metals showed that only minimal adhesion performances obtained from ECO coated metal for all formulation. If observed and compared among the coating that was added with ECO in their formulation, 10:90, 20:80 and 30:70,

Table 4. Results of adhesion X-Cut Tape Test of coated metal of EPO and ECO

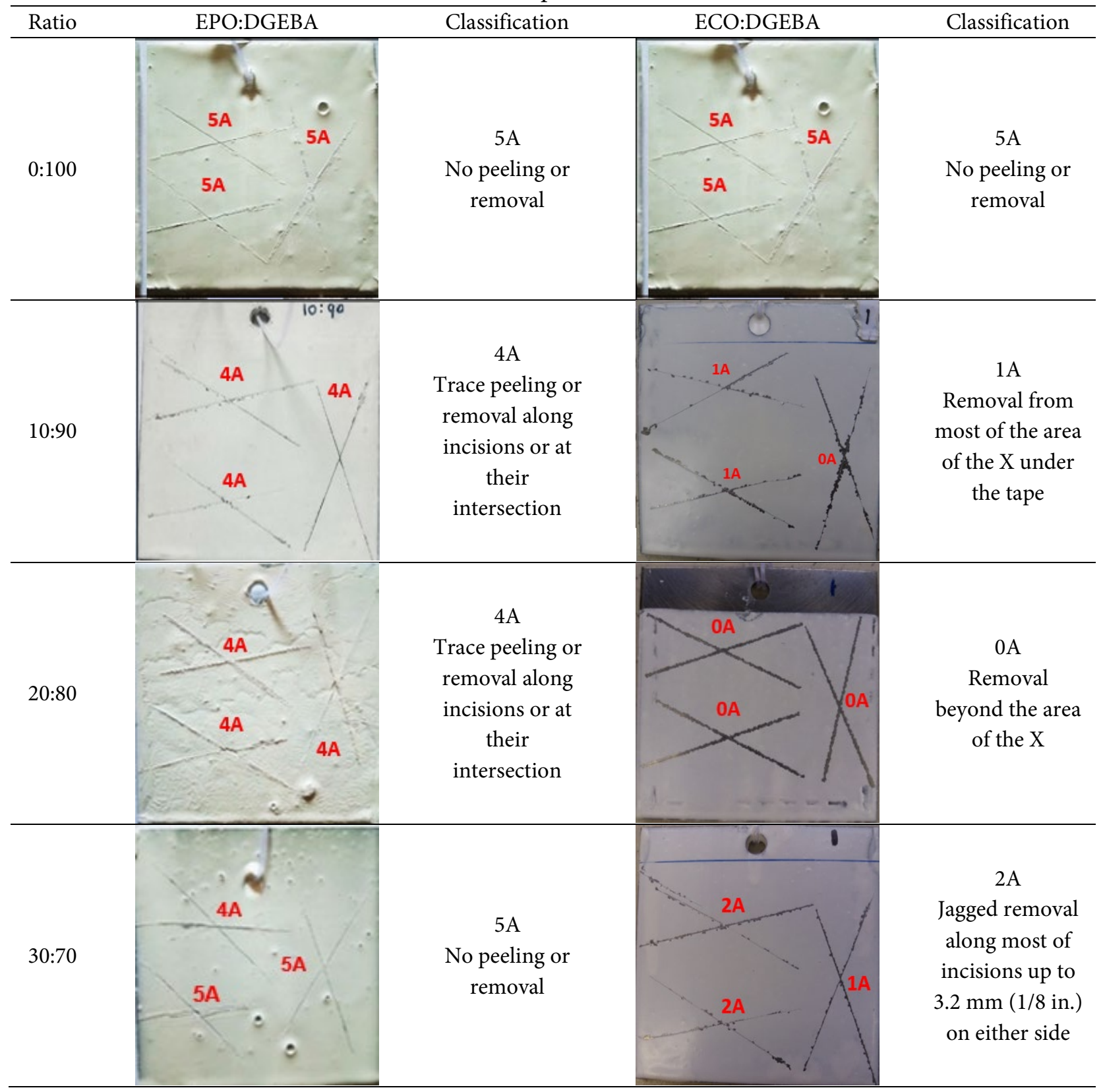


they obtained almost similar adhesion classification. Only formulation 20:80 yielded one rank lower than 10:90 and 30:70. There is no distinctive trend can be observed in result obtained from X-Cut Tape Test.

\section{Cross-Cut Tape Test}

Table 5 shows the condition of coated metal of EPO and ECO after being tested with Cross-Cut Tape Test.
The average percent area removed of coated metal was observed and calculated, then classified according to the standard ASTM D3359-09 in Table 2. As can be seen in Fig. 8 and Table 6, formulation 10:90(EPO: DGEBA) was classified as $3 \mathrm{~B}$ with minimum error bar of $2 \mathrm{~B}$, formulation 20:80 was classified as $4 \mathrm{~B}$ with minimum error bar of $3 \mathrm{~B}$ and formulation 30:70 was classified as $4 \mathrm{~B}$ with maximum error bar of $5 \mathrm{~B}$. Addition of $\mathrm{EPO}$ in the

Table 5. Result of adhesion Cross-Cut Tape Test of coated metal of EPO and ECO

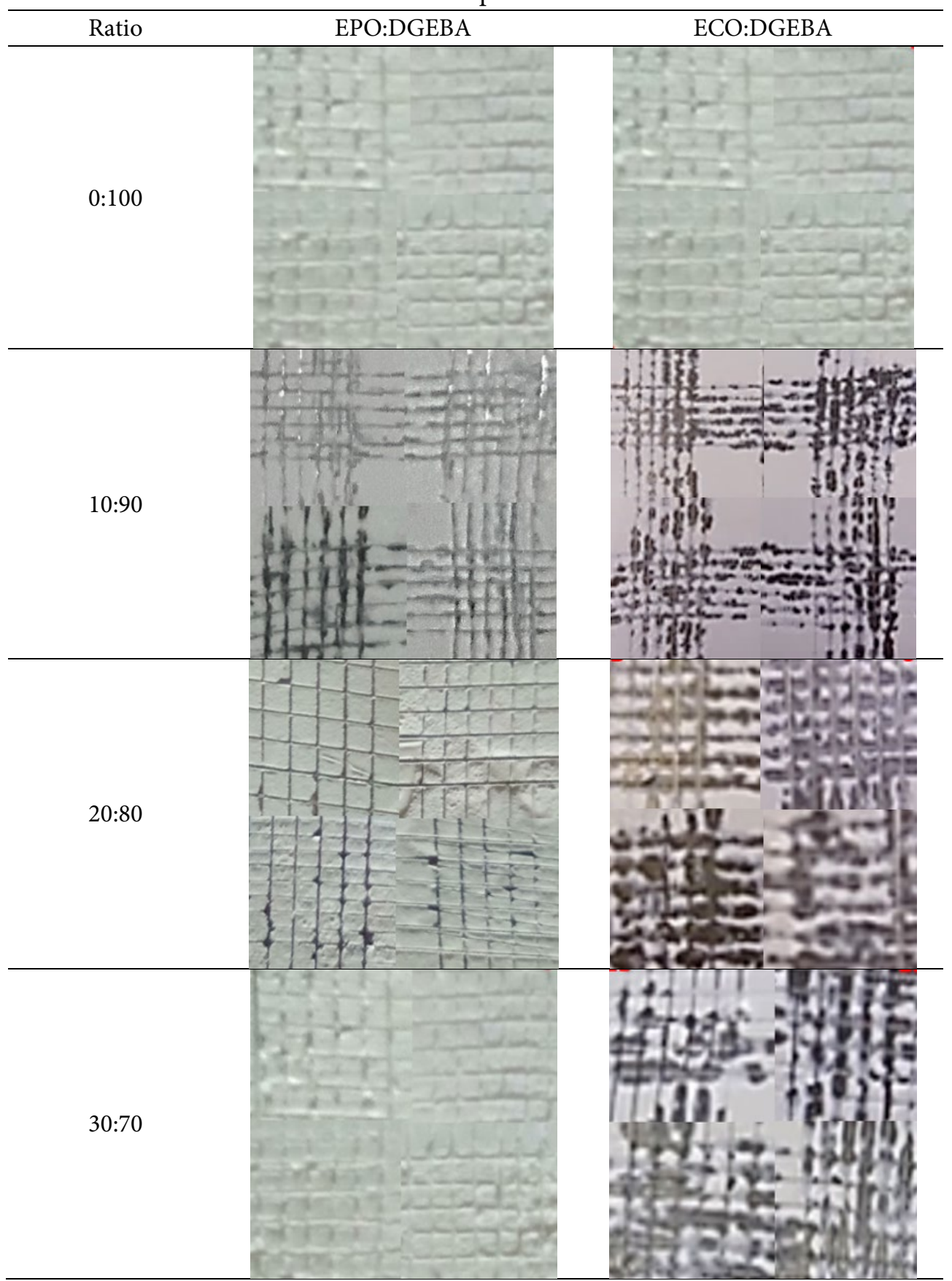




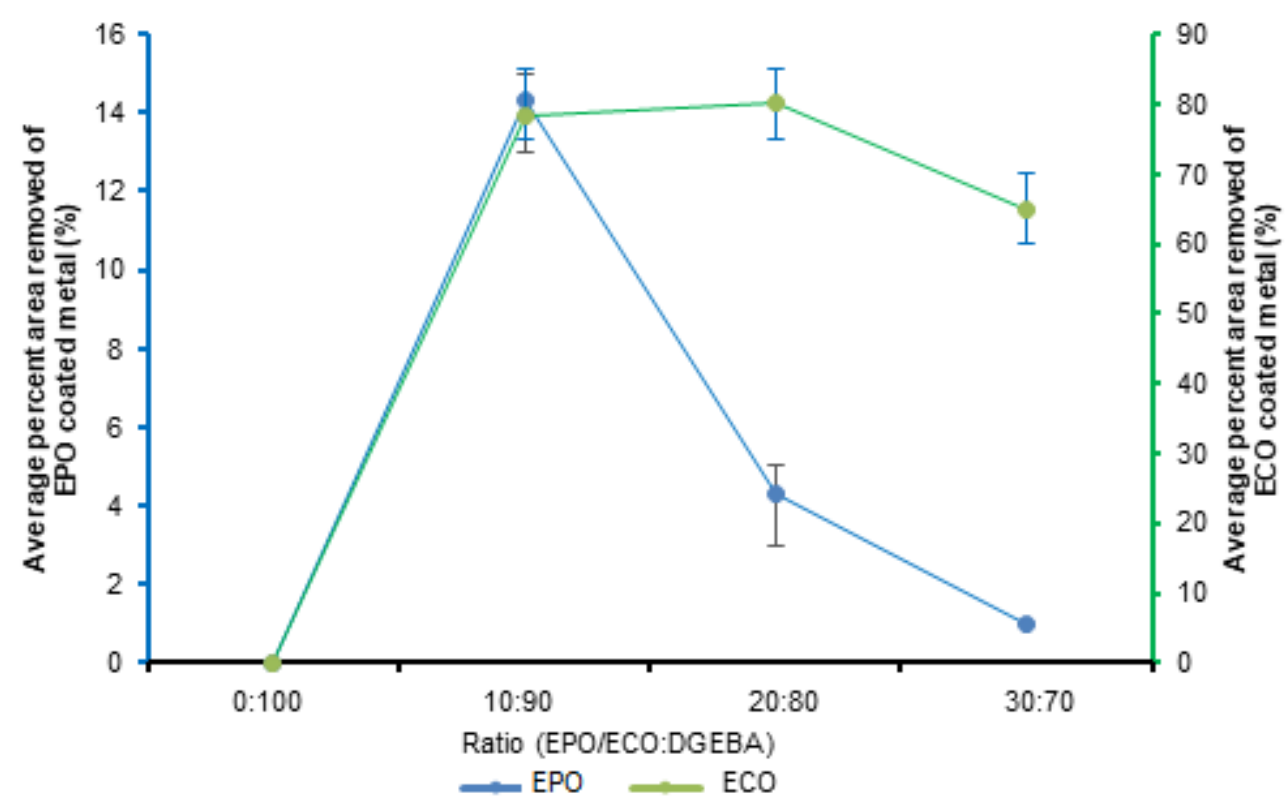

Fig 8. Graph of adhesion performance of developed coating by Cross-Cut Tape Test

Table 6. Summary of Cross-Cut Tape Test adhesion classification

\begin{tabular}{ccc}
\hline \multicolumn{3}{c}{ EPO:DGEBA } \\
\hline Ratio & Average Percent Area Removed (\%) & Classification \\
\hline $0: 100$ & 0 & $5 \mathrm{~B}$ \\
$10: 90$ & 14.33 & $3 \mathrm{~B}$ \\
$20: 80$ & 4.33 & $4 \mathrm{~B}$ \\
$30: 70$ & 1.0 & $4 \mathrm{~B}$ \\
\hline \multicolumn{3}{c}{} \\
\hline $0: 100$ & ECO:DGEBA & $5 \mathrm{~B}$ \\
$10: 90$ & 0 & $0 \mathrm{~B}$ \\
$20: 80$ & 78.33 & $0 \mathrm{~B}$ \\
$30: 70$ & 80.0 & $1 \mathrm{~B}$ \\
\hline
\end{tabular}

coating formulation have reduced the brittleness of the coating, as the components of EPO in the coating formulation increase, the adhesion performance become better. Meanwhile, only minimal adhesion performance obtained for all formulations of ECO:DGEBA. Both formulations (10:90 and 20:80) which was tested by Cross-Cut tape test were classified as $0 \mathrm{~B}$ and formulation 30:70 was classified as $1 \mathrm{~B}$. These adhesion results support the findings from FTIR analysis of epoxidized cooking oil in Fig. 7(b) that there is non-existence of oxirane ring in the epoxidized cooking oil which is important component to develop a good coating material.

\section{- CONCLUSION}

In this study, the unripe fruit bunch and used cooking oil was successfully utilized as additional compound in new epoxy formulation. Incorporation of these oils as additional component in formulating new epoxy coating gives oil palm a new area of application and adds value to this renewable resource. Comparison of FTIR analysis on unripe palm oil and used cooking oil before and after epoxidation show different results. Oxirane ring was present at a wavenumber $844 \mathrm{~cm}^{-1}$ in EPO whereas the oxirane ring was absent in ECO. The results obtained from the adhesion test from EPO were 
good as the coatings only experienced small trace of peeling. Only minimal adhesion performances obtained from ECO coated metal for all formulation. This correlated with absence of oxirane ring from the ECO observed in spectrum profile. Finally, it may be concluded that epoxidized unripe palm oil has a potential to replace petroleum-based resin in coating formulation based on their good performances.

\section{- ACKNOWLEDGMENTS}

This research was funded by Universiti Teknologi MARA (UiTM) under the MITRA PERDANA Grant Scheme, Grant No: 600-IRMI/PERDANA 5/3/MITRA (006/2018)-2.

\section{- REFERENCES}

[1] Fong, M.N.F., and Salimon, J., 2012, Epoxidation of palm kernel oil fatty acids, J. Sci. Technol., 4 (2), 87-98.

[2] Kumar, S., Samal, S.K., Mohanty, S., and Nayak, S.K., 2018, Toughening of petroleum based (DGEBA) epoxy resins with various renewable resources based flexible chains for high performance applications: A review, Ind. Eng. Chem. Res., 57 (8), 2711-2726.

[3] Inadera, H., 2015, Neurological effects of bisphenol A and its analogues, Int. J. Med. Sci., 12 (12), 926-936.

[4] Mínguez-Alarcón, L., Hauser, R., and Gaskins, A.J., 2016, Effects of bisphenol A on male and couple reproductive health: A review, Fertil. Steril., 106 (4), 864-870.

[5] Parashar, V., and Narula, A.K., 2015, Synthesis and characterization of DGEBA epoxy and novolac epoxy blends and studies on their curing and mechanical behavior, Knowl. Res., 2 (1), 30-36.

[6] Shi, L., Liu, Z., Li, J., and Qin, Z., 2017, Analysis of edible vegetable oils by infrared absorption spectrometry, Proceedings of the $20172^{\text {nd }}$ International Conference on Electrical, Automation and Mechanical Engineering (EAME 2017), 23-24 April 2017, Shanghai, China.

[7] Ahmad, S., Naqvi, F., Sharmin, E., and Verma, K.L., 2006, Development of amine-acid cured Annona squamosa oil epoxy anticorrosive polymeric coatings, Prog. Org. Coat., 55 (3), 268-275.
[8] Das, G., and Karak, N., 2009, Epoxidized Mesua ferrea $\mathrm{L}$. seed oil-based reactive diluent for BPA epoxy resin and their green nanocomposites, Prog. Org. Coat., 66 (1), 59-64.

[9] Meadows, S.S., Hosur, M.V., Tcherbi-Narteh, A., and Jeelani, S., 2017, Optimization studies on the synthesis and characterization of bio-based epoxidized soybean oil, The $21^{\text {st }}$ International Conference on Composite Materials (ICCM-21), 2025 August 2017, Xi'an, China.

[10] Jalil, M.J., Jamaludin, S.K., Azmi, I.S., and Daud, A.R.M., 2017, Characterisation of epoxidation of palm kernel oil based on crude oleic acid, Ind. Combust., 201606.

[11] Mancini, A., Imperlini, E., Nigro, E., Montagnese, C., Daniele, A., Orrù, S., and Buono, P., 2015, Biological and nutritional properties of palm oil and palmitic acid: Effects on health, Molecules, 20 (9), 17339-17361.

[12] Norhaizan, M.E., Hosseini, S., Gangadaran, S., Lee, S.T., Kapourchali, F.R., and Moghadasian, M.H., 2013, Palm oil: Features and applications, Lipid Technol., 25 (2), 39-42.

[13] Gunstone, F.D., 2002, Vegetable Oils in Food Technology: Composition, Properties and Uses, $1^{\text {st }}$ Ed., Blackwell, Hoboken, New Jersey.

[14] Omer, N.M.A., Ali, E.M.A., Mariod, A.A., and Mokhtar, M., 2014, Chemical reactions taken place during deep-fat frying and their products: A review, JNMS, 16 (1), 1-16.

[15] Bordin, K., Kunitake, M.T., Aracava, K.K., and Trindade, C.S., 2013, Changes in food caused by deep fat frying - A review, Arch. Latinoam. Nutr., 63 (1), 5-13.

[16] Donough, C.R., Cock, J., Oberthür, T., Indrasuara, K., Rahmadsyah, Gatot, A.R., and Dolong, T., 2015, Estimating oil content of commercially harvested oil palm fresh fruit bunches - A step towards increasing palm oil yields, Oil Palm Bull., 70, 8-12.

[17] Derawi, D., Salimon, J., and Ahmed, W.A., 2014, Preparation of epoxidized palm olein as renewable material by using peroxy acids, Malays. J. Anal. Sci., 18 (3), 584-591. 
[18] Fakhari, A., Rahmat, A.R., Wahit, M.U., and Kian, Y.S., 2014, Synthesis of new bio-based thermoset resin from palm oil, Adv. Mater. Res., 931-932, 78-82.

[19] Tajulruddin, W.N.W., Rahmat, A.R., Yusof, Z.A.M., and Fakhari, A., 2015, Characterization of polyol synthesized from epoxidized palm oil using Fourier transform infra-red and nuclear magnetic resonance, J. Adv. Res. Appl. Mech., 10 (1), 30-35.
[20] Sudheer, K., Sushanta, K.S., Smita, M., and Sanjay, K.N., 2017, Recent development of bio-based epoxy resins: A review, Polym. Plast. Technol. Eng., 57 (3), 133-155.

[21] ASTM D3359-07, Standard Test Methods for Measuring Adhesion by Tape Test, ASTM International, West Conshohocken, PA, 2007, https://www.astm.org. 